\title{
Port Harcourt Residents' Perception on Newspaper Coverage of Reproductive- Health Issues
}

\author{
Konye Cynthia Ikems \\ Linguistics and Communication Studies Department, Faculty of Humanities, University of Port Harcourt, Choba, \\ Rivers state
}

\section{ABSTRACT}

The study focused on investigating the perception of Port Harcourt residents' on newspaper coverage of reproductive health issues. Several studies have confirmed that newspapers report such stories, however no studies to the best of the researcher's knowledge has considered what people from this area think of such coverage. The objectives of the study were to find out their sources of information and their thoughts on the adequacy of the coverage given to reproductive health issues. The perception theory underpins the study, while survey research design was adopted to generate responses from 336 respondents. The purposive sampling technique was used to draw the sample questionnaire administration. Findings reveal that reproductive health messages are mostly obtained from family and friends, while newspapers had the least exposure. It was established that the coverage given to reproductive health issues is adequate, but does not influence their decision. This is possible as most of the people surveyed were between the ages of 18 and 35 years, and represent the sect in society with possible bad reading culture.

Keywords: Newspaper Coverage, Reproductive Health, Nigeria

DOI: $10.7176 / \mathrm{NMMC} / 89-04$

Publication date: April $30^{\text {th }} 2020$

\section{Introduction}

The human reproductive system is often affected by different health issues which if ignored could have adverse effect on economic development. This is probably the reason different levels of government are interested in the state of reproductive health in their domain. In 2005, United Nations Secretary General stated that 'sexual and reproductive health issues are to be included in national, regional, and international poverty reduction strategies, and sexual and reproductive health is central to reaching development goals'. This definition infers that sexual health is an aspect of reproductive health, based on this, some authors talk about them simultaneously. Sexual and reproductive health is not only a public health and a human rights issue. It is a developmental concern. This is why it was part of the Millennium Development Goals (2000-2015) and later added to the Sustainable Development Goals which was launched in 2015 to end in 2030.

Reproductive health issues affect every member of society, and are not restricted to only men and women. United Nations Population Fund stated that to maintain good reproductive health, people need access to accurate information... They must be informed and empowered to protect themselves from sexually transmitted diseases and other infections that are capable of affecting their reproductive organs. It is a major issue of concern all over the world, because it affects every member of society and is linked to the economic development of society.

Several meetings and campaigns have been launched over the years to handle reproductive health issues. In 1994, the International Conference on Population Development (ICPD) was convened in Cairo, Egypt with the intention of making relevant contributions toward controlling population growth. It was decided that the reproductive health of individuals and couples was key to managing population. This is however possible only if people are adequately informed of the necessary steps to take. All stakeholders were advised to devise means of achieving this goal.

The Nigerian government in 2005, produced the National Reproductive Health Policy with the aim of strengthening reproductive health activities in Nigeria and facilitating the achievement of relevant goals in this area. The government stated the different aspects of reproductive health it was interested in tackling, which are female genital mutilation, maternal and child health, HIV/AIDs. The document at the implementation stage also contained roles and responsibilities for different groups, including media.

Media are expected to create and maintain awareness of issues concerning reproductive health; promote the dissemination of information; make conscious effort to include reproductive health issues in their publications. Members of the public have the right to be informed of anything happening in their environment, inclusive of 
health. World Health Organisation (2008) asserted to this when it stated that men and women have the right to be informed of, and to have access to safe, effective, affordable, and acceptable methods of fertility regulation of their choice and right of access to appropriate health care services. Any means of communication can be used to inform members of the public. Media are one of the forms of communication engaged for this purpose.

Over the years, scholars have carried out numerous researches on either how media report health (reproductive health) issues or the perception of people on media coverage of such issues. Asemah (2012) conducted a study on the reach and impact of television communication on reproductive health in Anyigba, Kogi State, while Babatunde and Salau (2015) studied audience perception of Roll back malaria campaign in Kaduna metropolis: implication for maternal and child health in Nigeria. To the best of the researcher's knowledge, there are no studies in the area of reproductive health that has studied Port Harcourt residents' perception on coverage. Some authors suggest that studying how media disseminate information on issues also requires a survey of peoples' perception on media coverage of such issues. As earlier stated, media are expected to create awareness and publish stories on reproductive health. This research was therefore undertaken to investigate the thoughts of residents of Port Harcourt on newspaper coverage of reproductive health issues.

\section{Objectives of the study}

\section{The study is guided by the following:}

1. Examine the level of exposure of Port Harcourt residents to reproductive health messages in the newspapers.

2. Establish the perception of Port Harcourt residents on adequacy of newspaper coverage of reproductive health issues.

\section{Research questions}

The following research questions served as guide to the study:

1. What is the level of exposure of Port Harcourt residents to reproductive health messages in the newspapers?

2. How do Port Harcourt residents' perceive adequacy of newspaper coverage of reproductive health issues?

\section{Literature Review}

Perception theory lends itself to this study. The proponents of this theory are Berelson and Steiner (1964). The theory simply states that individuals have ways of shutting out information that is not in line with what they believe in. Weimann (2000) cited their definition of perception as the "complex process by which people select, organize, and interpret sensory stimulation into meaningful and coherent picture of the world" (p. 21). It simply means that individuals most often process media contents to suit the world view they are conversant with. According to Weimann, studies in human perception has shown that people's values, needs, beliefs and attitudes play important roles in determining how they select stimuli from the enormous media content in their environment and how they ascribe meaning to such stimuli from their existing frame of reference. According to Anaeto, Onabanjo, and Osifeso (2008) this theory shows that the process of interpreting messages is complex and that these goals may be difficult to achieve (p. 66).

Perception as it were, is subjective, and therefore individualistic in nature. Whether implicitly or explicitly, the individual's ability to 'choose' which stimuli he will perceive has been portrayed as a filter through which all forms of communication must pass through. This means that people screen media contents in such a way that it makes it easy for them to take what they like and discard what they dislike. For Weimann, an unconscious filtration process therefore comes into operation, when there is need for an individual to choose what to pay attention to out of the various information he is exposed to. This filtering process is also referred to as the 'ways' through which people 'consume' contents of the media they have an inkling for and avoid the ones that are contrary.

Baker (1976) opines that perception can be influenced by countless psychological factors including the predispositions of individuals that are based on their past experience, cultural expectations, motivations, moods and attitudes. All these factors are responsible for why people watch or listen or read certain things and ignore 
others. He added that the concepts of selective attention, selective exposure, selective perception, and selective retention were formulated to explain how individuals manage and manipulate media messages available to them. Baran and Davis (2015) refer to them as the selective processes. They are 'the defense mechanisms that we routinely use to protect ourselves (and our egos) from information that would threaten us' (p. 106). Every individual would likely go through these processes whenever there is information in the media. They decide if they are interested in the issue being discussed based on their existing belief or standard, if it is, only then will they let their defense mechanisms down. Anaeto, Onabanjo, and Osifeso (2008) refer to it as perception theory. They claim that the 'process of interpreting messages is complex and that these goals maybe difficult to achieve' (p.56). The process of selecting / filtering information can be cumbersome as result of any of the following: age, religious belief, social or economic class, education/literacy level, or level of exposure or ignorance of the individual. Some information might be okay based on ones economic status, but not good enough based on the doctrines that guide the person's religious beliefs. Baran and Davis (2015) also agree that the selective processes are 'complex and highly sophisticated filtering mechanisms that screen out useless sensory data, while quickly identifying and highlighting most useful patterns in the data'. Baran (2004) opines that the selective processes is one of the attitude change theories, which helps us select what information we consume, remember, and interpret as personally important and idiosyncratic ways (, p.425). From the above, we deduce that the process involves different actions/ stages which include, selective exposure, selective retention, and selective exposure.

\section{Selective Exposure}

Baran and Davis (2015) state that people's tendency to expose themselves to or attend to media messages that they feel are in accord with their already held-attitudes and interests and the parallel tendency to avoid that which might be dissonance-creating' (p. 106). People are more inclined to open their hearts to information that are consistent with what they believe, and look for a way of escaping from messages that have contrary views. Daramola (2003) opines that a person has the tendency to expose him or herself to communications that are in agreement with the person's existing attitudes and to avoid those communications that are not'. The communication component is an embodiment of so much, because so much can be shared in a communication act. They include but not limited to information, messages, views, and ideas. Selective exposure is the process by which people expose themselves to only those messages which are consistent with their preexisting attitudes and beliefs (Baran, 2004).

The authors concur that individuals will not expose themselves to messages that are in contrast with their attitudes and beliefs. This study intends to find out if Port Harcourt residents expose themselves to media contents that have to do with reproductive health issues.

\section{Selective Attention}

For Baran (2004), selective attention is concerned with how people give attention to messages that are in line with their preexisting attitudes and beliefs. Daramola (2003) states that people will screen out other media content which they have little or no interest in and attend to what they like. When a person decides to take some parts of a message and leave out the rest, they have automatically chosen what they are comfortable with.

\section{Selective Retention}

Audiences tend to remember information that they like and are not contrary to morals, values, needs, and knowledge. Baran (2004) assumes that people remember best and longest those messages that are consistent with their preexisting attitudes and beliefs (p. 425). There are people who can still remember advertisements they saw years ago because it appealed to them. Over the years, many campaigns have been run to enlightening members of the public about the negative consequences of ignoring healthy reproductive practices. More of these campaigns will be produced because the quest to enthrone quality reproductive health for all is still on.

\section{Selective Perception}

Baran and Davis (2014) define selective perception as the mental and psychological recasting of a message so that its meaning is in line with a person's beliefs and attitudes (p. 107). Once a person has exposed and given attention to media messages, analysing the message becomes the next thing. This is to ensure that the message is beneficial in the end. Baran (2004) predicts that people will interpret messages in a manner consistent with their preexisting attitudes and beliefs. The attitudes and beliefs of people will always guide the basis for interpreting messages obtained from media. 
. DeFleur and DeFleur (2016) assume that both attention to media presentation and perception of content are highly selective'. Before an individual decides to ponder on a message, he would have screened it to make sure that it is cognizant with what they believe in or are comfortable with. People have to depend on the selective processes because of the multitude of messages available in the media. These processes are very important in the communication act. It is one thing for the media or sender to produce messages it is another thing for the target audience to get it as intended, and act in like manner.

At the end of the study, this research will show if media have reported reproductive health issues in such a way that they gave Port Harcourt residents' something to 'think about' and in turn promote national development. This is because reproductive health, which is an aspect of health, is an important indicator for development.

\section{Perception}

Peoples' individual differences usually manifest in the way they behave and react to issues they are exposed to. The stories covered by the media are always interpreted or understood in different ways by individuals based on their idiosyncrasies. The way a message is presented and interpreted by the participants in a communication act can affect the communication process.

Communication research has abundantly demonstrated that the success or failure of the communication process depends as much on the members of the audience and their predisposition as it depends on the content of the stimulus and the manner of its presentation...Each member of the audience consciously or not modifies the stimulus he perceives according to his own predisposition (Cooper and Dinerman 2003, p.30).

From the foregoing, it is obvious that interpretation and understanding of issues are dependent on disposition, which influences effective communication. Otara (2011) opines that the way people interpret issues is based on what they way feel about what happens around them, which in turn influences their response or reaction. Perception is our sensory experience of the world around us and involves both the recognition of environmental stimuli and actions in response to these stimuli. It is also important to recognize that every person has a unique frame of reference that includes all of the internal and external factors that affect behaviour. Interpretation of their experiences is dependent on many factors not directly related to their immediate situation. This study therefore intends to find out what Port Harcourt residents' think about newspaper coverage of reproductive health issues. Media reports have the capacity to invoke positive or negative emotions or interpretations from its audience.

\section{Health communication channels}

The use of various channels of communication to spread health messages is defined as health communication. Parvanta (2011) cited the Department of Health and Human Services definition of health communication 'as the study of the use of communication strategies to influence individual and community decisions that enhance health' (p.3). This makes reference to the fact that all communication that are focused on health are disseminated with the intention to informing members of the public, as well as influencing them to make necessary changes based on factual information. Torkkola (2016) defined health communication from two broad perspectives which are based on social and cultural practices. This means that definitions of health communication can fall into any of the broad classifications above.

Health communication as both a social and cultural practice,(i) point out that ill health are constructed in all kinds of communication. From official health policy document health news, medical literature, and consultation to television dramas, advertisements, web pages, and everyday chat on health and illness.(111) healths are produced in different levels and types of communication such as mass communication, health journalism, interpersonal communication, and organisational communication (p.24).

Reference is made to the different sources of information on health issues or the channels through which these messages get to individuals. This study is concerned about how newspapers report stories that are healthrelated. Ahmed and Bales (2016) are of the opinion that 'media are certainly an integral health information source(s), as they define illness and health, feature services, and products that can help consumers manage their 
health, and provide a representation of others who have specific conditions to a large number of individuals ( $\mathrm{p}$. 20). Mass media have an important role to play when it comes to the dissemination of health information. Parvanta and Harner (2011) asserted to this by saying that health communication uses multiple channels and approaches, which, despite what some people may think include, but not limited to the use of the mass media (p.17). The media as a result of its capacity to reach an audience that is heterogeneous and scattered is most often used to inform members of the public about inherent health issues that may or may not affect them. Thomas (2006) opined that health communication encompasses the study and the use of communication strategies to inform and influence individuals and community knowledge, attitudes and practices with regards to health and health care (p.1). it is important to discuss the various channels through reproductive health messages can be disseminated in this study, because reproductive health is an aspect of health.

\section{Empirical Review}

Babtunde and Salau (2015) carried out a research on audience perception of Roll Back Malaria Campaign in Kaduna metropolis: implication for maternal and child health in Nigeria. The objectives of the research were to determine the variations in levels of source confidence among the vulnerable group and to find out how the campaign has been useful in influencing attitude towards malaria prevention among the vulnerable group. Health belief model was the theory adopted in the study and questionnaire was the research instrument used for data collection. Pregnant women formed the population of study; purposive sampling method was adopted to reach one hundred and eighty (180) respondents. The study showed that the roll back malaria campaign changed the views and perceptions of the respondents' about the use of mosquito nets and other beliefs they have about malaria. Whereas Babatunde and Salau's (2015) study considered campaigns on roll back malaria and the perception of pregnant women, the current study was conducted to ascertain the perception of Port Harcourt residents' on newspaper coverage of reproductive health issues. Both studies adopted survey research design because it was necessary to ascertain audience perception of certain issues.

\section{Methodology}

The survey research design was used to obtain data from Port Harcourt residents on their perception of newspaper coverage of reproductive health issues. Survey research is described as the study of both large and small populations by selecting and studying samples chosen from a population to discover the relative incidences, distribution and interactions of sociological and psychological variables (Okwechime, 2016). The research design was appropriate for the study because there was need to know the thoughts of the public on newspaper coverage of reproductive health issues, since newspaper contents are published for the public consumption. The questionnaire was the research instrument used and it was divided into two sections: demographic and psychographic.

The entire population of Rivers state was used, which is 6,498,395 (six million, four hundred and ninetyeight thousand, three hundred and ninety-five). This was as a result of $2.5 \%$ growth rate put forward by the National Bureau of statistics in 2016. The age range for this study was made up of those between eighteen (18) and fortyfive (45) years. Three hundred and eighty four copies of the questionnaire were administered and three hundred and thirty six (336) retrieved with the aid of five research assistants. Qualitative and quantitative methods of data analysis were adopted for the study. Tables were used to present data obtained from the questionnaire which was on a modified 4-point scale that is as follows:

$\begin{array}{lr}\text { Strongly Agree (SA) } & 4 \text { points } \\ \text { Agree (A) } & 3 \text { points } \\ \text { Disagree (D) } & 2 \text { points } \\ \text { Strongly Disagree (SD) } & 1 \text { point. }\end{array}$

The mean score of 2.5 points was arrived at after mean calculation, $(4+3+2+1=10 / 4)$. The Weighted Mean Score (WMS) was calculated using the formula below. So, any mean score that was 2.5 and above was taken as the respondents having a positive stance on the statement and accepted, while any mean score below 2.5 indicated that the respondents disagree with the statement, and this led to its rejection. Weighted mean score $(\mathrm{WMS})=\frac{\sum \mathrm{FX}}{\sum \mathrm{F}}$ 
Data Presentation

Table 1: Demographic characteristics of respondents

\begin{tabular}{llll}
\hline & Characteristics & N & \% \\
\hline Sex & Female & 229 & 68.2 \\
& Male & 107 & 31.8 \\
\hline Age & Below 18 & 5 & 1.5 \\
& $18-25$ & 196 & 58.3 \\
& $26-35$ & 77 & 22.9 \\
& $36-45$ & 44 & 13.1 \\
& 46 and above & 14 & 4.2 \\
\hline
\end{tabular}

$\mathrm{n}=336$

From the table above $42 \%$ of the respondents were male. This is imperative because reproductive health issues affect both men and women, so having men as one third of the respondents is a good implication. Majority $(94.3 \%)$ of the respondents were within the age of 15 and 45 years old who are young, energetic and probably sexually active, and can learn from events happening around them.

Research question 1: what is the level of exposure of Port Harcourt residents to reproductive health messages?

Table 2: Port Harcourt residents' response on level of exposure to reproductive health

\begin{tabular}{lllllll}
\hline Statement & SA & A & D & SD & Total & $\begin{array}{l}\text { WMS } \\
\text { Decision }\end{array}$ \\
\hline $\begin{array}{l}\text { People learn about reproductive health from } \\
\text { family and friends }\end{array}$ & 132 & 146 & 18 & 9 & 305 & 3.3 \\
& $(43.3)$ & $(47.9)$ & $(5.9)$ & $(3)$ & $(100)$ & $\begin{array}{l}\text { Accepted } \\
\text { People learn about reproductive health from }\end{array}$ \\
$\begin{array}{l}\text { television } \\
\text { People learn about reproductive health from }\end{array}$ & $(38.9)$ & $(57.9)$ & $(4.6)$ & $(6.7)$ & $(100)$ & Accepted \\
radio & $(29.8)$ & $(54.5)$ & $(9.1)$ & $(6.5)$ & $(100)$ & Accepted \\
$\begin{array}{l}\text { People learn about reproductive health from } \\
\text { newspapers }\end{array}$ & 52 & 136 & 37 & 27 & 252 & 2.8 \\
Total & $(20.6)$ & $(53.9)$ & $(14.7)$ & $(10.7)$ & $(100)$ & Accepted \\
\hline
\end{tabular}

The numbers in parentheses are percentages

Table 2 indicates that $91 \%$ of the respondents learnt about reproductive health from their family and friends, while $89 \%$ were informed from television contents. The respondents who learnt about reproductive health from radio were $89 \%$ and $75 \%$ for newspapers. It is obvious that friends and family were their major source of reproductive health messages and newspapers were their least source of reproductive health messages. This may be because $58 \%$ of the respondents are between the age of 18 and 25, who spend most of their time on the internet (social media. The results of the weighted mean score also corroborates respondents' agreement on obtaining reproductive health message from different sources, but indicates. Newspapers however, had the lowest value of 2.8 compared to $3.3 \mathrm{WMS}$ of family and friends. It is pertinent to state that even thought different channels of communication can be used for the dissemination of reproductive health messages, family and friends is the best option. Interpersonal form of communication is very vital for the dissemination of reproductive health messages. 
Research question 2: How do Port Harcourt residents perceive adequacy of newspaper coverage on reproductive health issues?

Table 3: Port Harcourt residents' perception on the adequacy of newspaper coverage on reproductive health.

\begin{tabular}{|c|c|c|c|c|c|c|}
\hline Statement & SA & $\mathbf{A}$ & D & SD & Total & WMS \\
\hline \multirow{2}{*}{$\begin{array}{l}\text { Newspaper is a viable tool for dissemination of } \\
\text { information on reproductive health }\end{array}$} & 65 & 110 & 42 & 36 & 253 & 2.8 \\
\hline & (25.7) & $(43.5)$ & 12.5 & 16.6 & 100 & Accepted \\
\hline \multirow{2}{*}{$\begin{array}{l}\text { Response on newspaper reading encourages } \\
\text { positive reproductive health practices }\end{array}$} & 51 & 112 & 53 & 33 & 249 & 2.7 \\
\hline & (20.5) & (44.9) & 21.2 & 13.0 & 100 & Accepted \\
\hline \multirow{2}{*}{$\begin{array}{l}\text { Newspaper influence the decision people make } \\
\text { regarding their reproductive health }\end{array}$} & 50 & 68 & 51 & 71 & 240 & 2.4 \\
\hline & (20.8) & (28.3) & (21.3) & (29.6) & 100 & Rejected \\
\hline \multirow{2}{*}{$\begin{array}{l}\text { Language used in reporting health stories } \\
\text { affects understanding }\end{array}$} & 88 & 114 & 42 & 26 & 296 & 2.7 \\
\hline & (29.7) & 38.5 & 14.2 & 9.8 & 100 & Accepted \\
\hline \multirow{2}{*}{$\begin{array}{l}\text { Newspaper coverage of reproductive health } \\
\text { issues is adequate }\end{array}$} & 77 & 101 & 45 & 35 & 258 & 2.9 \\
\hline & (29.8) & 39.1 & 17.4 & 13.6 & 100 & Accepted \\
\hline \multirow{2}{*}{$\begin{array}{l}\text { People resort to newspaper for latest } \\
\text { information on reproductive health }\end{array}$} & 65 & 90 & 48 & 48 & 251 & 2.7 \\
\hline & (25.9) & 35.9 & 19.1 & 19.1 & 100 & Accepted \\
\hline
\end{tabular}

\section{The numbers in parentheses are percentages}

A greater part of the respondents that is $70 \%$ were in support of the idea that newspapers were viable tools for the dissemination of reproductive messages. After the calculation of the WMS, the decision arrived at was accepted because the calculated value (2.8) was more than the normal mean (2.5). The table also shows $66 \%$ which is a significant portion of the respondents' are in support of the fact that reading newspapers encourages people to engage in healthy reproductive practices. The weighted mean score also confirmed the statement, because 2.8 signify it is accepted. The respondents did not believe that reading newspapers influenced their reproductive health decisions. The WMS result of 2.4 implies the statement is rejected, because it is lower than the 2.5 mean for the study. From the result presentation in table 4.8, $69 \% \mathrm{f}$ the respondents are certain that their understanding of health stories can be hampered by the language used in its publication. The 2.9 WMS value lent credence to this. It can be deduced from the table that a fair number of the respondents are positive about referring to newspapers when they need information about reproductive health. This has also been validated by the 3.2 result obtained from the WMS.

\section{Discussion}

Communication is a pivotal tool for the transformation of human lives and knowing how to get the most out of it will be of immense benefit to the society. The channel or medium through which a message is disseminated is very essential in the communication act. Hassan (2013) asserted to this by stating that the channel is an important component of the communication process, because it is the vehicle through which messages are carried in the sender-receiver continuum. It was based on this that the researcher thought it wise to find out the various channels through which the respondents' got reproductive health information or messages.

From the data available in table 2, it was obvious that the respondents got their reproductive health messages from the different sources - family and friends, television, radio and newspapers. This means that Port Harcourt residents are exposed to reproductive health messages. The finding confirms what Parvanta and Harner (2011) stated about health communication using multiple channels and approaches, which, despite what some people may think include, but not limited to the use of the mass media. Torkkola (2016) claimed that health communication has three definitions and it is the third one that is established by this study. He claims that health 
messages are produced in different levels and forms of communication, such as mass communication, interpersonal communication, health journalism, and organizational communication. Although, respondents obtained reproductive health messages from the listed channels, newspaper had the lowest response. Family and friends, which happens to be a form of personal communication (interpersonal) was an indispensable source of reproductive health messages. It is evident from the foregoing that residents' of Port Harcourt metropolis perceive all media channels as sources of messages on reproductive health, including interpersonal (family and friends) form communication.

\section{Objective 2}

Establish the perception of Port Harcourt residents on adequacy of newspaper coverage of reproductive health issues.

People have different perception of issues based on their idiosyncrasies, which can also influence the way they interpret messages. The perception theory states that people expose themselves to information that is in consonance with their beliefs and this influences their understanding. Baran and Davis (2015) stated that people's tendency to expose themselves to or attend to media messages that they feel are in accord with their already heldattitudes and interests and the parallel tendency to avoid that which might be dissonance-creating'. From the responses gotten, it can be inferred that residents of Port Harcourt metropolis do know about reproductive health issues.

The data in table 3 was used for this objective. Most of the respondents were in support of newspaper being a viable tool for the dissemination of reproductive health messages. It also indicates that people actually do read newspapers with the sole aim of getting reproductive health messages. This verifies what the perception theory states about people not exposing themselves to media contents except they are congruent with their preexisting beliefs or way of life. It was also observed from their responses that newspaper coverage of reproductive health issues was adequate in terms of the kind of information published. The respondents however did not agree that what they read in newspapers influenced the decisions they made. This may be attributed to the fact that $81 \%$ of the respondents were between the ages of 18 and 35 , who spend most of their time on social media. Their attitude towards reading newspapers is poor.

In selective exposure, individuals can decide to expose themselves to media content, but that does not mean that they must do what they have read. The result of the weighted mean score was 2.4 , which was below the critical value 2.5. Therefore, the statement about newspaper content being able to influence people's decision was rejected. This corroborated the stipulations of perception theory about people's ability to pay attention to media information, but not allow the information to move them to the point where they have to change their stance on issues. DeFleur and DeFleur (2016) claimed that both attention to media presentation and perception of content are highly selective'.

Based on the information in table 3, it can be inferred that $68 \%$ of the respondents perceived that language used in the coverage of reproductive health stories impeded understanding. This lent credence to what Waisbord and Obregon (2012) stated about the technicality of reporting health related stories for the understanding of the lay man. Due to the complex nature of medical and scientific information, health news reporting demands technical knowledge that is sometimes owing to newsroom routines or the lack of specialization of a media professional, beyond the reporters who ordinarily cover health news. It is clear that the stories published in newspapers usually encourage people to engage in positive reproductive health practices. Arulchelvan (2016) affirmed this when he stated that media messages are expected to promote healthy behaviour by providing information and encouragement. The respondents' line of thought also confirmed what Dare (2000) stated about the capacity of the print media to teach skills, reinforce desirable attitudes and discourage bad ones. The print media according to him are vehicles of non-formal education. We can confidently say at this point that residents' of Port Harcourt metropolis are positive about the role newspapers play in the dissemination of reproductive health messages. It was only in the area of these messages influencing their decisions that majority disagreed. This lends credence to the tenets of the perception theory which states that messages are passed through various filters which in turn influence conclusions arrived at.

\section{Conclusion}

Reproductive health is an indices for development that is why governments and international agencies are interested in curbing issues related to it. Over the years it has been established that various means of 
communication can be engaged in the spread of such messages. The consequences of the findings of the study has shown that newspapers are the least patronised source of reproductive health message. This could be because most youths are social media users, who have poor reading habits. However, interpersonal form of communication is the best means of dissemination reproductive health messages. Port Harcourt residents agree that newspaper coverage of reproductive health issues is adequate, but they are not in any way influenced by what they read. This confirms that the selective processes is an attitude change theory, which helps an individual select what information to consume, remember, and interpret as personally important.

\section{References}

Anaeto, S. G., Onobanjo, O. S. \& Osiefso, J. B. (2008). Models and theories of communication. USA: African renaissance books

Asemah, E,S, (2012).The reach and impact of television communication on reproductive health in Anyigba, Kogi State, Nigeria. In journal of Linguistics and Communication studies.2(11)

Babatunde,V.O. \& Salau, S.(2015). Audience perception of roll back malaria campaign in Kaduna metropolis. Inmplication for maternal and child health in Nigera, In Nigerian journal of communication.12(1), p. 122.

Bales, R.B. and Ahmed, R..(2016). Health communication and mass media;an integrative approach to

Baran, J. \& Davis, D. K. (2015) ( $\left.7^{\text {th }} \mathrm{ed}.\right)$. Mass communication theory foundations, ferment and future: USA:Cenage learning.

Baran, J.(2004). Introduction to mass com media literacy and culture ( $\left.3^{\text {rd ed. }}\right)$ New York: McGraw-Hill

Cooper,E. \& Diinerman, H.(2003).Analysis of the film don't be a sucker: a study in communication. In Brooker, W. and Jermyn,D. (Eds.). The audience studies reader.London: Routledge

Daramola, I. (2003). Introduction to mass communication 2(ed.) Lagos, Rothan Press Ltd.

Defluer,M. \& Defluer,M.H.(2016). Mass communication theories: explaining origins, processes and effects. New York: Routeledge

Hassan,S.(2 $2^{\text {nd }}$ ).(2013). Mass communication principles and concepts. New Delhi: CBS Publishers and distributors Pvt ltd.

Okwechime, C.(2016).Mass media research management $2^{\text {nd }}$ ed.Lagos:McBolm publishers

Otara, A.(2011). Perception:a guide for managers and leaders. Journal of management and strategy. 2(3), pp 2124

Parvanta,C. (2011). Introduction. In Parvanta, C.F., Nelson,D. E., Parvanta,S. \& Harner, R.N. Essentials of public health communication. USA: Jones and Bartlett learning

Thomas,R.K.(2006).Health communication. New York: Springer science + Business media Inc.

Torkkola,S.(2016).Multifaceted health communication. In Marinescu, V. and Mitu.B.(Eds.). Health and the media: Essays on the effects of mass communication. North Carolinas: McFarland and company Inc. publishers

Weinmann,G.(2000). Communicating unreality: modern media and the reconstruction of reality. Carlifonia: Sage publications Inc.

World Health Organisation. (2008). Closing the gap in a generation: Health equity through action on social determinant of health. 